Opinion

\title{
Cardiovascular complications of novel Wuhan Coronavirus (COVID-19) - A 2020 update
}

Keywords: novel wuhan coronavirus, COVID-19, respiratory syndrome, toacute myocarditis, acute myocardial infarction

\section{Opinion}

Novel Wuhan Coronavirus (COVID-19) induced unusual viral pneumonia was first reported in Wuhan city, China during December 2020. Milder version of coronavirus like severe acute respiratory syndrome coronavirus (SARS-CoV) with mortality of $10 \%$ and the Middle East respiratory syndrome coronavirus (MERS-CoV) with mortality of $37 \%$ were reported earlier. Acute respiratory distress syndrome with cytokine storm may be the reason for increased mortality in Novel Wuhan Coronavirus COVID-19. Clinical presentation of Novel Wuhan Coronavirus COVID-19 is similar to SARS but the mortality rate is documented high among the COVID-19 patients. $^{1,2}$

Upto $40 \%$ of the admitted COVID-19 patients had cardio-vascular diseases. Elevated cardiac troponin which is suggestive of virus load induced cardiac injury was seen in $7.2 \%$ of admitted patients. Arrythmias were seen in $16.7 \%$. Known coronary artery disease and heart failure patients are at a higher risk when compared to others. We can expect cardiac arrest due toacute myocarditis, acute myocardial infarction, and rapid-onset heart failure. ${ }^{3}$ In previous outbreaks of SARS/MERS patients with HFrEF had higher requirement of ventilators. ${ }^{4}$ As of now there is no anti-viral treatment proven to be effective for Novel Wuhan Coronavirus COVID-19. Lopinavir and Ritonavir is widely using as per its previous data on SARS and MERS. Use of steroids is controversial as it has no proven benefits on mortality.

\section{Acknowledgments}

None.

\section{Conflicts of interest}

The authors declare that they have no conflicts of interest.

\section{Funding}

None.

\author{
Volume I 3 Issue I - 2020 \\ Rajesh Rajan, Mohammed Al Jarallah, Raja
Dashti
Department of Cardiology,Al-Amiri Hospital, Kuwait
}

Correspondence: Dr. Rajesh Rajan, Department of Cardiology, Sabah Al Ahmad Cardiac Center, Amiri Hospital, Kuwait, Email cardiology08@gmail.com

Received: February 18, 2020 | Published: February 24, 2020

\section{Author's contributions}

Rajesh Rajan participated in data analysis and manuscript preparation. Mohammed Al Jarallah participated in manuscript preparation. Raja Dashti participated in the drafting of manuscript. All authors have read and approved the manuscript.

\section{References}

1. Huang C, Wang Y, Li X, et al. Clinical features of patients infected with 2019 novel coronavirus in Wuhan, China. Lancet. 2020;395(10223):497506 .

2. Lu R, Zhao X, Li J, et al. Genomic characterisation and epidemiology of 2019 novel coronavirus: implications for virus origins and receptor binding. Lancet. 2020;395(10224):565-574.

3. Wang D, Hu B, Hu C, et al. Clinical Characteristics of 138 Hospitalized Patients with 2019 Novel Coronavirus-Infected Pneumonia in Wuhan, China. JAMA. 2020;10.1001/jama.2020.1585.

4. Li SS, Cheng C, Fu C, et al. Left Ventricular Performance in Patients with Severe Acute Respiratory Syndrome: A 30-Day Echocardiographic Follow-Up Study. Circulation. 2003;108(15):r93-r98. 